\title{
Analysis of Trace Elements in Aluminium by Neutron Activation Determination of Uranium in Aluminium -
}

\author{
Masatoshi Kobayashi, Sumiko Nagatsuka, and Kunihiko Higashi \\ Tokyo Metropolitan Isotope Research Centre \\ Received October 24, 1964
}

\begin{abstract}
${ }^{239} \mathrm{~Np}$, which is produced by the thermal neutron activation of uranium 238 (neutron flux $1.7 \times 10^{12} \mathrm{n} / \mathrm{cm}^{2} \cdot \mathrm{sec}$ ), was extracted selectively by $T T A$ benzene solution under a suitable acid condition. Measuring the activity of ${ }^{239} \mathrm{~Np}$, we were able to determine 0.1 to $0.2 \mathrm{ppm}$ of uranium in high purity aluminium. In this method, extraction of $\mathrm{U}, \mathrm{Pu}$ or $\mathrm{Pa}$ was negligible and that of Sc was less than 3\%. This method enables a rapid and simple procedure and permits the determination of as small amount of uranium as $0.03 \mathrm{ppm}$ in aluminium.
\end{abstract}

\section{Introduction}

It is a matter of importance to establish a rapid and simple determination method of trace elements in aluminium either for metallurgical study or for analytical chemistry.

As for uranium, Kobayashi, M., et al. ${ }^{1)}$ reported in their metallurgical study of uranium in aluminium on the distribution curves of uranium in Al-U alloy determined by means of nondestractive activation analysis after zone refining.

Microgram of uranium in aluminium metal, however, has not been determined by usual nondestructive activation analysis.

We examined the availability of activation analysis with chemical separation to the determination of uranium in aluminium.

\section{Descriptions on the nuclear data and chemical separation of nep- tunium}

Methods for the determination of uranium are based on the fission of ${ }^{235} \mathrm{U}$ or the activation of ${ }^{238} \mathrm{U}$ and ${ }^{234} \mathrm{U}$.

The percentage abundance of these isotopes are $0.72,99.27$ and $0.006 \%$, respectively, and the nuclear reactions of these isotopes with thermal neutrons can be summarized as follows :

$$
\begin{aligned}
& { }^{234} \mathrm{U}(n, \gamma){ }^{235} \mathrm{U} \\
& { }^{235} \mathrm{U}(n, f) \text { fission products } \\
& { }^{238} \mathrm{U}(n, \gamma){ }^{239} \mathrm{U} \frac{\beta^{-}}{23.5 \mathrm{~min}} \rightarrow{ }^{239} \mathrm{~Np} \frac{\beta^{-}}{2.33 \text { day }} \rightarrow
\end{aligned}
$$

$$
{ }^{239} \mathrm{Pu} \frac{\alpha}{24,360 \mathrm{y}}{ }^{235} \mathrm{U}
$$

In the reaction (1), the amount of ${ }^{235} \mathrm{U}$ activity produced from ${ }^{234} \mathrm{U}$ is negligible in the case of short-time irradiation because the halflife of ${ }^{235} \mathrm{U}$ is very long and the percentage abundance is very small.

The reaction (2) was studied by Seyfang and Smales ${ }^{2)}$, who used the method based on the separation of one of the fission products ${ }^{140} \mathrm{Ba}$ (half-life 12.8 days), meanwhile $\mathrm{Ph}$. Albert ${ }^{3)}$ determined uranium in aluminium by ${ }^{132} \mathrm{Te}$ (half-life 77 hours).

By the reaction (3), uranium in ores and soils was determined by Mahlman and Leddicotte ${ }^{4)}$ using the precipitation method of ${ }^{239} \mathrm{~Np}$, and W. D. Mackintosh, et al. ${ }^{5)}$ determined uranium in aluminium by ${ }^{239} \mathrm{U}$ (half-life 23.5 $\min$ ).

From the results of these investigations, ${ }^{23} \mathrm{~Np}$ was considered as the best radionuclide to be used in radiochemical separation procedure.

\section{Radiochemical purification of neptunium}

As to radiochemical separation of neptunium, there are many imethods, such as the precipitation, the solvent extraction and the ion exchange procedure etc. ${ }^{6}$, among which the extraction method is considered to be favourable for its rapidity.

Neptunium may be extracted from an aque ous phase by ethyl ether, tributyl phosphate, ketones and a number of the glycol-ether type of solvent, while other actinides or rare earths are, however also extracted by these solvents 
and these elements often cause the interference in neptunium determination.

From diluted acid solution, neptunium (IN) is readily extracted by benzene solution of 2thenoyltrifluoroacetone (TTA) together with comparatively little interfering ions among those mentioned above.

Besides neptunium, only a few elements such as $\operatorname{Zr}(\mathbb{I}), \mathrm{Ce}(\mathbb{N}), \mathrm{Hf}(\mathbb{I}), \mathrm{Fe}(\mathbb{I}), \mathrm{Pa}(\nabla), \mathrm{Sn}$ (N) and $U(\mathbb{N})$ are extracted from the solution which is acidic enough $\left(0.5 \mathrm{MH}^{+}\right)$.

Therefore TTA extraction was adopted after preliminary isolation by lantanium fluoride or by ether extraction.

\section{Experimental}

\section{Irradiation}

Weighed portions of the sample of aluminium (purity is 99.99\%) and the comparative standard $\left(\mathrm{U}_{3} \mathrm{O}_{8}\right)$ were put into aluminium foil and then wrapped in a thin polyethylene bag.

They were irradiated in the thermal neutron flux of approximately $1.7 \times 10^{12} \mathrm{n} / \mathrm{cm}^{2} \cdot \mathrm{sec}$ of the reactor (center hole) at Tokyo Atomic Industrial Research Laboratory.

The period of irradiation was selected to 30 hours. After irradiation, the samples were alowed to be cooled for about 2 days and were processed chemically as described below.

\section{Solvent extraction of ${ }^{239} \mathrm{~Np}$ with TTA}

The irradiated samples were dissolved in $20 \%$ sodium hydroxide solution to make the solution acidic, to which $10 \mathrm{mg}$ of lanthanum carrier and $0.2 \mathrm{ml}$ of $5 \mathrm{M}$ hydroxylamine hydrochloride solution were added and the mixture was stirred for 5 minutes. The solution was neutralized with $20 \%$ sodium hydroxide to precipitate lanthanum hydroxide, after which the mixture was centrifuged and the supernatant liquid was discarded.

The precipitate of lanthanum hydroxide was dissolved in $2 M$ hydrochloric acid to which $20 \%$ sodium hydroxide solution was added to reprecipitate lanthanum hydroxide. After the filtration the precipitate was dissolved in $2 \mathrm{ml}$ of $2 M$ hydrochloric acid to which $1 \mathrm{ml}$ of concentrated hydrofluoric acid was added to pre- cipitate lanthanum fluoride. After centrifugation, the supernatant liquid was discarded and the precipitate was washed with small amount of $1 M$ hydrochloric acid-1 $M$ nitric acid, then the lanthanum fluoride was dissolved in saturated boric acid solution and $6 \mathrm{M}$ nitric acid solution.

Nitrate ion in the solution was eliminated by evaporations with concentrated hydrochloric acid and the solution was made $5 \mathrm{M}$ in $\mathrm{HCl}$, $0.1 M$ in $\mathrm{KI}, 0.1 M$ in hydroxylamine hydrochloride. This solution was heated for $2 \sim 3$ minutes.

The solution was diluted to $0.5 \mathrm{M}$ hydrochloric acid solution, from which neptunium was extracted with an equal volume of $0.15 M$ solution of TTA in benzene by shaking for 30 minutes.

The standard sample of uranium oxide $\left(\mathbf{U}_{3}\right.$ $\mathrm{O}_{8}$ ) was also dissolved in dil. nitric acid and an aliquot of the solution was processed under the same conditions as the sample.

\section{Measurements and determination of sepa- rated ${ }^{239} \mathbf{N p}$}

The radioactivity of ${ }^{239} \mathrm{~Np}$ in benzene solution was measured with the 512 channels $\gamma$-ray spectrometer, type ND 130, constructed by Nuclear Data Corporation.

The sample and the comparative standard were irradiated simultaneously, chemically processed and counted under similar conditions, then the amount of uranium in the sample can be calculated as follows:

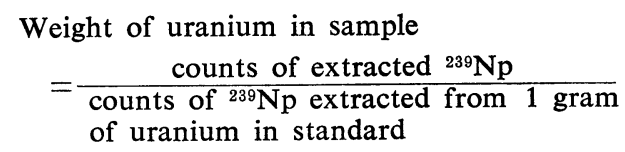

\section{Results and discussions}

Fig. 1 shows the $\gamma$-ray spectrum of high purity aluminium after 30 hours' irradiation, in which only one photoelectric peak can be observed at $1.37 \mathrm{MeV}$, which shows the presence of ${ }^{24} \mathrm{Na}$.

Meanwhile Fig. 2 shows the $\gamma$-ray spectrum of lanthanum fluoride which was separated from the sample solution.

In this $\gamma$-ray spectrum can be observed the photoelectric peaks of rare earths and actinides which were coprecipitated with lanthanum: 


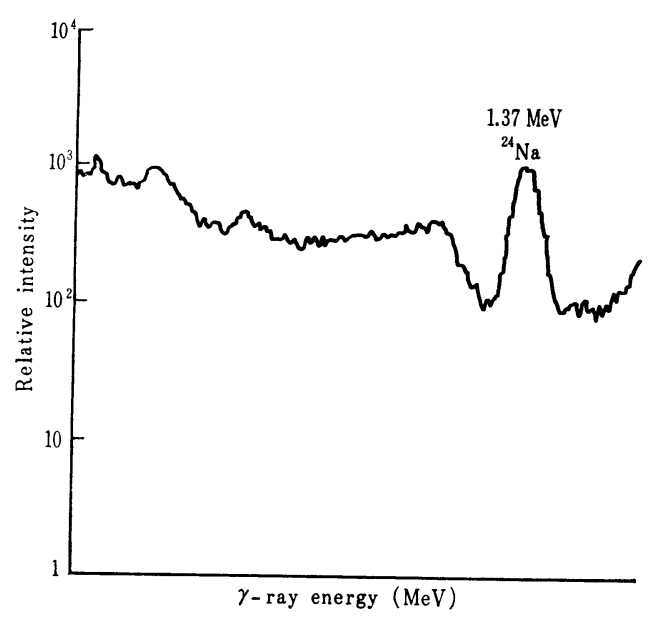

Fig. 1 The $\gamma$-ray spectrum of high purity aluminium irradiated for 30 hours and then cooled for 69 hours.

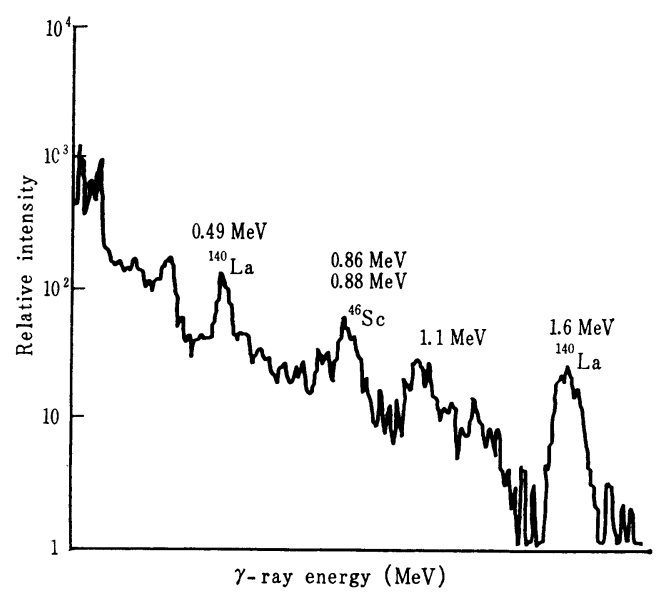

Fig. 2 The $\gamma$-ray spectrum of lanthanum fluoride separated from aluminium.

peaks of ${ }^{239} \mathrm{~Np}$ and ${ }^{153} \mathrm{Sm}$ around $0.1 \mathrm{MeV}$, peaks of ${ }^{140} \mathrm{La}$ at $0.49,0.86$ and $1.6 \mathrm{MeV}$, peaks of ${ }^{46} \mathrm{Sc}$ around $0.8 \mathrm{MeV}$ and at $1.1 \mathrm{MeV}$.

The $\gamma$-ray spectrum of ${ }^{239} \mathrm{~Np}$ in the extracted fraction is shown in Fig. 3(1), which shows similar figures with that of ${ }^{239} \mathrm{~Np}$ in the extract of the standard sample (Fig. 3(2))

The half-life of the photoelectric peak at $0.105 \mathrm{MeV}$ of the extracted fraction from the sample also shows good accordance with that of ${ }^{239} \mathrm{~Np}$ as is shown by the decay curve in Fig. 4.

The analytical results of uranium content in high purity aluminium are shown in Table 1.

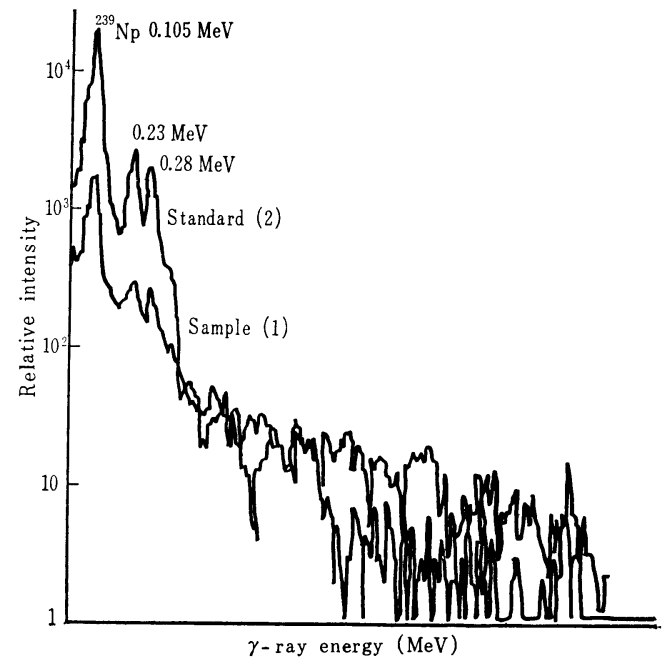

Fig. 3 The $\gamma$-ray spectra of ${ }^{239} \mathrm{~Np}$ extracts from aluminium and from uranium oxide.

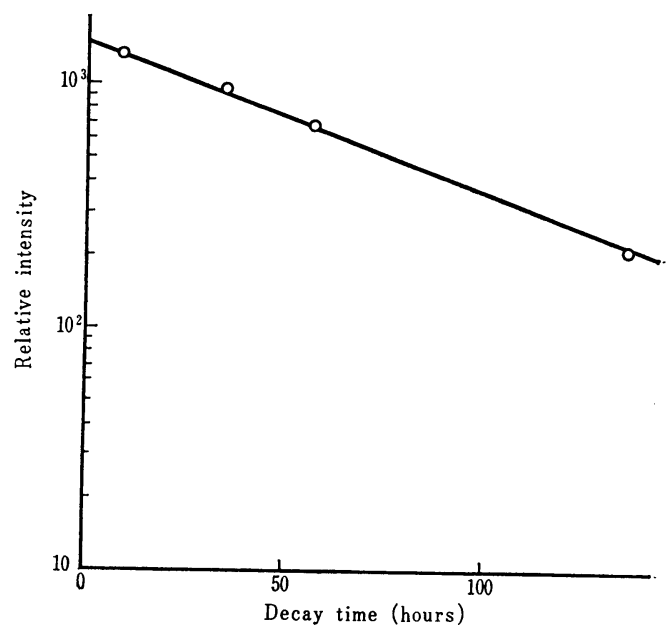

Fig. 4. The decay curve of ${ }^{239} \mathrm{~Np}$ extracted from sample.

Table 1 Analytical results of uranium content in high purity aluminium

\begin{tabular}{c|c|c|c}
\hline Sample & $\begin{array}{c}\text { Weight } \\
(\mathrm{g})\end{array}$ & $\begin{array}{c}\text { Activity } \\
(\mathrm{cpm})\end{array}$ & $\begin{array}{c}\text { Content } \\
(\mathrm{ppm})\end{array}$ \\
\hline A & 1.083 & 676 & 0.22 \\
A & 1.099 & 594 & 0.20 \\
A & 0.934 & 528 & 0.20 \\
B & 0.943 & 269 & 0.10 \\
\hline
\end{tabular}

In order to establish the extraction method of neptunium by TTA, ${ }^{239} \mathrm{~Np}$ which was produced from irradiated uranium oxide, was used as tracer. 
The yield of extraction of neptunium was more than $90 \%$.

Although uranium (IV) and plutonium (IV) are also readily extracted by benzene solution of TTA from acid solution, the reduction of uranium to uranium $(\mathbb{N})$ is very slight under these conditions and plutonium is reduced to plutonium (II). Neptunium (IV), which is produced by rapid reduction of neptunium, is stable under these conditions.

Scandium, one of the impurity elements in aluminium which can be activated easily, is also extracted by $0.5 \mathrm{M}$ TTA benzene solution at $\mathrm{pH} 1.5$, but the amount of scandium extracted by this method was found to be less than $3 \%$ by using ${ }^{46} \mathrm{Sc}$ as tracer.

Thorium also exists in aluminium as impurity element together with uranium and rare earths.

${ }^{233} \mathrm{~Pa}$, produced from ${ }^{232} \mathrm{Th}$ through the reaction shown below, is also extracted from the strong acid solution by $0.4 M$ TTA benzene solution.

$$
{ }^{232} \mathrm{Th}(n, \gamma){ }^{233} \mathrm{Th} \frac{\beta^{-}}{23.5 \mathrm{~min}}{ }^{233} \mathrm{~Pa} \frac{\beta^{-}}{27.4 \text { day }}{ }^{233} \mathrm{U}
$$

In this method, however, the spectrum of ${ }^{23} \mathrm{~Pa}$ in the ${ }^{239} \mathrm{~Np}$ fraction was not recognized even after cooling of ${ }^{239} \mathrm{~Np}$ activity and had no interference (Fig. 5).

\section{Conclusion}

In the study on the systematic determination of trace elements in aluminium by the activa. tion analysis, the methods for $\mathrm{Cu}, \mathrm{Ga}, \mathrm{Sb}, \mathrm{Fe}$, $\mathrm{Zn}, \mathrm{Sc}, \mathrm{Cd}$ etc. were reported previously in the annual report 1963 .

This paper deals with the determination method for uranium in aluminium by extrac. tion using TTA benzene solution.

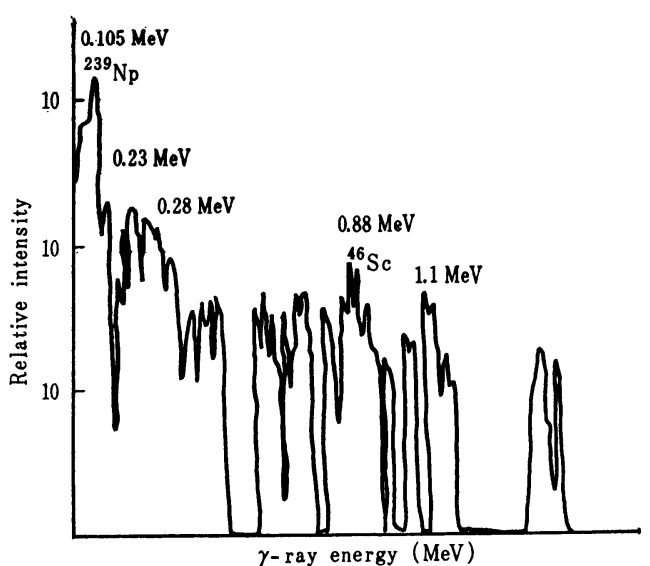

Fig. 5 The $\gamma$-ray spectrum of ${ }^{239} \mathrm{~Np}$ extracted from aluminium cooled for 12 days.

This method enables the comparatively rapid and simple procedure and permits the determination of as small amount of uranium as $0.03 \mathrm{ppm}$ in aluminium.

\section{References}

1) Kobayashi, M., Kurosu, H. : Annual Report of the Tokyo Metropolitan Isotope Centre, 2, 81 (1963)

2) Seyfang, A.P. and Smales, A.A.: Analyst, 78, 394 (1953)

3) Albert, P.: Proceedings of the 1961 International Conference "Modern Trends in Activation Analysis", p.86

4) Mahlman, H.A. and Leddicotte, G.W.: Anal. Chem., 27, 823 (1955)

5) Mackintosh, W.D. and Jervis, R.E.: Canadian Atomic Energy Report, No. AECL-481 (1957)

6) Hyde, E.K. : Proceedings of the International Conference on the Peaceful Uses of Atomic Energy, 7, 281 (1955) 
はすでに発表したが,ここではアルミニウム中のウランの定量について検討した。 ${ }^{238} \mathrm{U} の(n, \gamma)$ 反応によって生成される ${ }^{239} \mathrm{U}$ の壊変による ${ }^{239} \mathrm{~Np}$ を $0.5 M$ 塩酸溶液から $0.15 M$ TTA ベンゼン 溶液に抽出することによって，比較的簡単に分離測定することができた。熱中性子束密度 $1.7 \times$ $10^{12} \mathrm{n} / \mathrm{cm}^{2} \cdot \sec て ゙ 30$ 時間照射し，高純度アルミニウム中の $0.1 \sim 0.2 \mathrm{ppm}$ のウランを定量した。本 法によれば U, Pu, Pa の妨害は無視することができ, $\mathrm{Sc}$ はこの条件では抽出率 $3 \%$ \%下なので ほとんど妨害にならなかった。 